\title{
A JOVEM PIANISTA, A DISTINTA AMADORA, A DILETANTE: NOTAS SOBRE O APAGAMENTO DO FAZER MUSICAL FEMININO COMO PROFISSÃO
}

\author{
THE YOUNG WOMAN PIANIST, THE DISTINGUISHED AMATEUR, THE DILETTANTE: \\ NOTES ON THE ERASURE OF FEMALE MUSIC MAKING AS A PROFESSION
}

LA JOVEN PIANISTA, LA DISTINGUIDA AFICIONADA, LA DILETANTE: NOTAS
SOBRE EL BORRADO DE LA CREACIÓN MUSICAL FEMENINA COMO PROFESIÓN

Patricia Amorim de Paula ${ }^{1}$

\begin{abstract}
Resumo: Este artigo apresenta como objeto de análise a atuação de mulheres na música na cidade do Rio de Janeiro durante o século XIX. Trata especificamente de um conjunto de 206 musicistas encontrado por meio das páginas da imprensa oitocentista, cujo legado não gozou de paridade ao compor os registros históricos da música brasileira. Portanto, é preciso se perguntar o que levou o legado de tantas mulheres profissionais da música ao apagamento. Para tanto, desenvolve-se como argumento os impactos da palavra-chave amadorismo como ideia aplicada às musicistas aprisionando-as numa espécie de condição permanente e restritiva.
\end{abstract}

Palavras-chave: Musicistas; imprensa oitocentista; Rio de Janeiro.

Abstract: This article presents as its object of analysis the performance of women in music in the city of Rio de Janeiro during nineteenth century. It specifically addresses a group of 206 female musicians discovered by means of pages of nineteenth century's press, whose legacy did not enjoy of parity to the compose the historic registers of Brazilian music. Therefore, one needs to wonder what took the legacy of so many professional women in music to the erasure. Thereby, the argument is developed through the impacts of the keyword amateurism as an idea applied to female musicians, imprisoning them in a kind of permanent and restrictive condition. Keywords: Female musicians; nineteenth century's press; Rio de Janeiro.

Resumen: Este artículo presenta como objeto de análisis el desempeño de las mujeres en la música en la ciudad de Río de Janeiro durante el siglo XIX. Aborda específicamente un grupo de 206 mujeres músicas descubiertas mediante páginas de la prensa del siglo XIX, cuyo legado no gozó de paridad para componer los registros históricos de la música brasileña. Por tanto, es necesario preguntarse o qué llevó a la borradura del legado de tantas mujeres profesionales de la música. De esta manera, se desarrolla como argumento los impactos de la palabra clave amateurismo como idea aplicada a las mujeres músicas, encerrándolas en una especie de condición permanente y restrictiva.

Palabras clave: Mujeres músicas; prensa del siglo XIX; Rio de Janeiro.

\section{Introdução}

Como instância de consagração, a historiografia musical, até hoje, apresenta poucos registros sobre a participação feminina no cenário musical carioca do Oitocentos. Muito embora saibamos que a constituição de grupos sociais artísticos brasileiros nesse tempo e espaço contou com a participação social de ambos os sexos, este problema eminentemente sociológico da ausência de mulheres musicistas na historiografia ainda carece de reflexão. Tentando reparar

\footnotetext{
${ }^{1}$ Faculdade de Educação da Unicamp.
} 
parcialmente esse vazio, o texto enfatizará o trabalho musical feminino, algo que aponta para o surgimento de uma profissão possível para as mulheres no século XIX.

O convite feito pelo presente texto consiste em analisar a ação dessas musicistas na sociedade fluminense do Oitocentos como uma expressão do feminismo nascente nesse período $^{2}$. Porque compreender a luta delas pela sobrevivência e sustento familiar por meio da música configura um modo não convencional de reação das mulheres e, afinal, foram modos de resistir e refazer a imagem sobre o ser feminino na Capital do Império do Brasil.

E para tornar conhecido esse contingente feminino, faço uso de um método de investigação envolvendo a pesquisa de palavras-chave na Hemeroteca da Fundação Biblioteca Nacional no interior de algumas páginas da imprensa oitocentista. Tal método se inspira nas análises de Raymond Williams (2007) sobre o contexto inglês, que, guardadas as devidas proporções, foi reorientado para a compreensão do contexto brasileiro através da pesquisa em fontes primárias. O método das palavras-chave se torna um instrumento analítico relevante ao dar ênfase ao vocabulário geral que uma dada sociedade compartilhava nas suas mais variadas áreas de reflexão e de experiência e, desse modo, permitir a entrada na estrutura de sentimentos da época, ainda que por aproximação, análise e interpretação. A partir das palavras-chave "pianista", "compositora" e "professora de piano" foi possível registrar vasta quantidade de material a ser analisado: anúncios de procura e de oferta de trabalho, matérias, programas de concerto, críticas e obras das musicistas encontradas. Trato especificamente de um conjunto de 122 compositoras, aproximadamente 386 obras, das quais obtive cópias de 107 obras editadas e algumas delas manuscritas, e de 84 professoras de piano e de canto, lembrando que a maior parte delas também trabalhou como intérprete e como compositora.

Cabe salientar que boa parte das profissionais da música não foram localizadas por meio das palavras "compositora" e "pianista", mas sim como "professora de piano", embora atuassem também nessas outras funções. A partir dessa compreensão subtende-se que havia pouca aceitação ao fato de elas serem compositoras e pianistas intérpretes, sobretudo até os anos finais do século XIX.

$\mathrm{O}$ encontro dos nomes dessas musicistas e de seus tempos de vida permitiu nova forma de exploração dessa fonte primária, que colabora para um trabalho analítico das trajetórias por meio da reunião de dados biográficos. A periodização adotada para a realização do mapeamento dos itinerários das musicistas pesquisadas foi de 1820 a 1889.

Privilegio os jornais como fonte de pesquisa por serem compreendidos como meio de comunicação mais popular, como objetos culturais, voltados a assuntos ordinários de interesse comum e transmitidos no vernáculo. Nesse sentido, a linguagem escrita é pensada aqui como prática social e a ela está atrelado o desenvolvimento dos sentimentos populares de um tempo passado (LUCA, 2016). Contudo, convém prevenir que se trata de um trabalho minucioso e árduo que não necessariamente irá recuperar as trajetórias de todas essas profissionais, afinal, o contexto de vida e produção dessas artistas mulheres é atravessado por apagamentos, informalidades e filtros seletivos empreendidos pelo patriarcado. Além disso, a própria documentação encontrada direciona o olhar sobre algumas artistas em detrimento de outras.

Entretanto, diante de tão expressivo contingente de artistas descobertas, é preciso se perguntar o que levou o legado de tantas mulheres profissionais da música ao apagamento, à decadência. Aparentemente, a palavra-chave amadora, como ideia, teve impacto substancial sobre a trajetória das profissionais da música, pelo menos até onde foi possível remontar essa relação durante a pesquisa. Sendo assim, encaminharei a discussão nesse sentido a fim de conhecer e reconstituir essas trajetórias profissionais, enfatizando como a negação do fazer

\footnotetext{
${ }^{2}$ Seguem os nomes de alguns periódicos que debatiam temas ligados ao feminismo: Jornal das Senhoras (18521855); O Sexo Feminino (1875-1877 e retomado de 1877-1889); A Família (1889-1897); Jornal das Damas (1890); A Mensageira (1897-1900); O Quinze de Novembro do Sexo Feminino (1890-1896) (BUITONI, 1981).
} 
musical feminino como profissão foi ostensivamente praticada pelo patriarcado e como isso repercutiu para o esquecimento desse legado pelos registros históricos da música brasileira.

\section{A jovem pianista, a distinta amadora, a diletante - as múltiplas faces do amadorismo aplicado às musicistas}

Ter a música como distração, como passatempo refinado, era algo desejável e recomendável à educação das mulheres, esse conteúdo fazia parte do plano de estudos voltado ao público feminino. Até certo ponto, a profissão em si, especialmente como professora de piano, não representava o abandono das funções tradicionais esperadas, como esposas e mães. O problema apareceu quando a profissional se destacou na função pública como intérprete e como compositora, em um período em que se discutia se as mulheres eram ou não dotadas das mesmas capacidades intelectuais dos homens. Nesse sentido, ser musicista implicava em deparar-se com uma série de reservas e estereótipos na vida diária.

Em outras palavras devemos dizer, reiterando a socióloga Ana Paula Simioni (2008), que o sentido da palavra amadorismo não era objetivo, não congregava músicos ou musicistas sem experiência, como a palavra sugere, não demarcava tempos e espaços formativos diversos. A palavra estava mais intimamente ligada às expectativas diversas com respeito às ocupações masculinas e femininas, ou seja, seu uso era orientado pela lógica de gênero.

Para exemplificar com trajetórias analisadas nessa pesquisa, podemos ver a seguir como se materializava a dificuldade em concebê-las como profissionais plenamente formadas. Iniciaremos com o caso de Amelia de Mesquita (1866-1954).

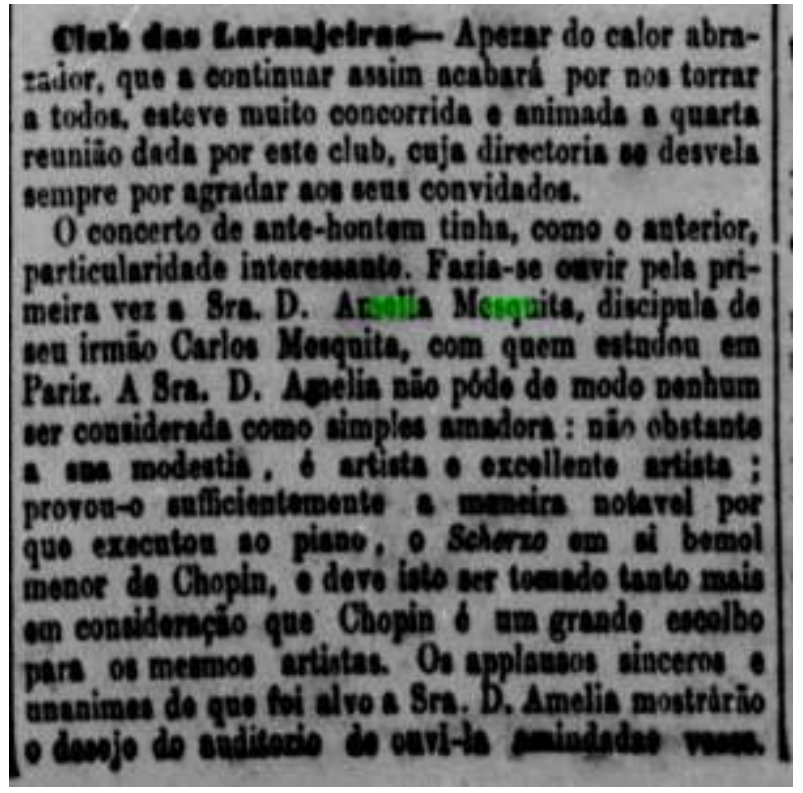

Figura 1: Sobre o concerto no Club das Laranjeiras

Fonte: Jornal do Commercio, RJ, anno 63, n. 360, 28 de dezembro de 1885, p. 1.

Na figura 1, embora a crítica tenha reconhecido os méritos da artista e afirme que pela performance da intérprete a mesma não pudesse ser considerada uma amadora: "não póde de modo algum ser considerada como simples amadora: não obstante a sua modéstia, é artista e excellente artista", o texto sugere que Amelia tenha sido somente discípula de seu irmão, e que ela foi a Paris por este motivo: "discipula de seu irmão Carlos Mesquita (1854-1953), com quem estudou em Pariz", enaltecendo no caso a figura de Carlos e apagando a trajetória de 
formação da pianista. Cabe mencionar que, em 1877, o irmão e ela foram com a família para Paris, com o objetivo de que pudessem ingressar no Conservatório de Música de Paris. Ele ingressou primeiro e ela um ano depois. Amelia estudou com os mesmos professores de seu irmão: piano com Antoine-François Marmontel, harmonia com Émile Durand e órgão com César Franck, e retornou ao Rio de Janeiro já formada em 1885.

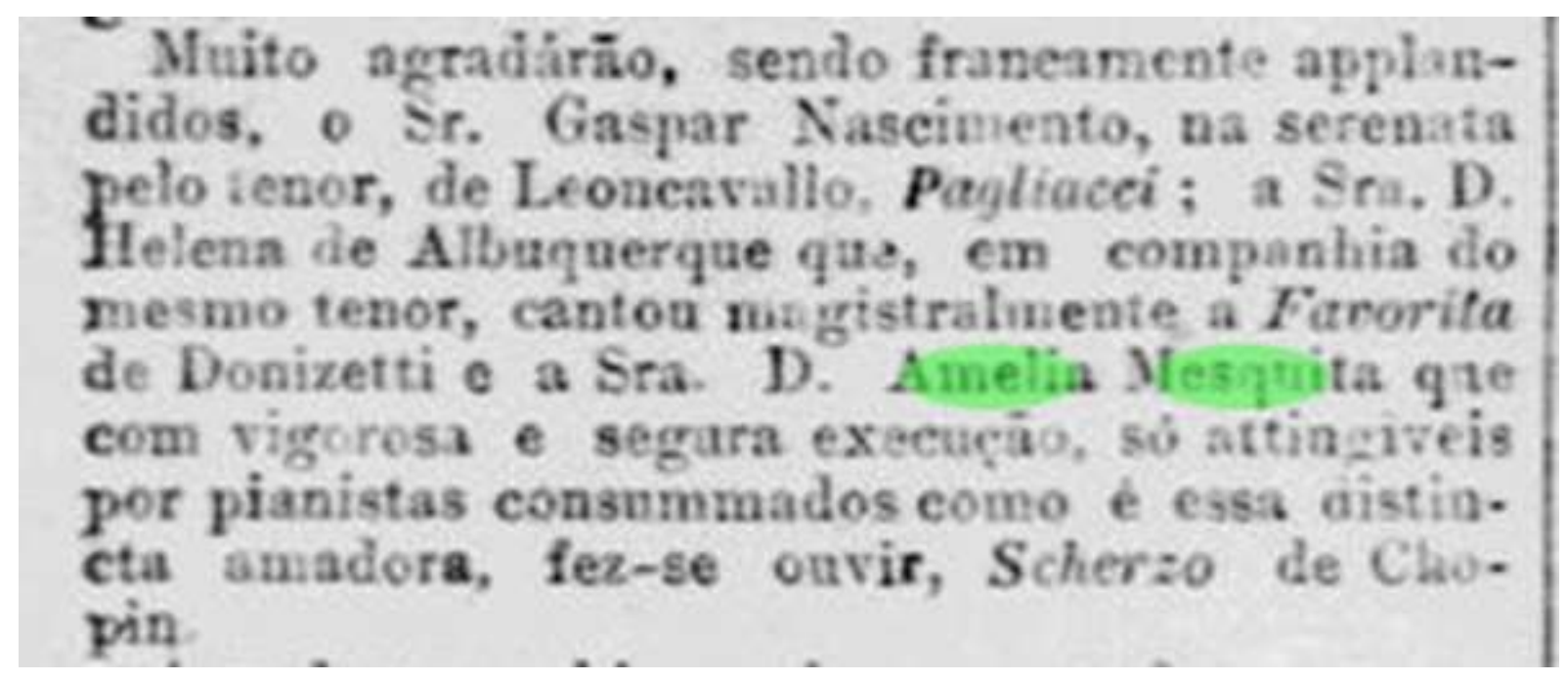

Figura 2: Sobre a $2^{\mathrm{a}}$ matinée-concertante em Petropolis

Fonte: Jornal do Commercio, RJ, n. 82, 23 de março de 1897, p. 3.

Na figura 2, 12 anos depois de formada, ou seja, com tempo significativo de experiência na carreira, a crítica refere-se a ela de modo ambíguo: "pianista consumada" e "distinta amadora", nitidamente uma caracterização controversa.

\begin{tabular}{l|l} 
No Episodio Symphlnnico a 2 pianns, & \\
que Mesquita executou com sua ta & \\
lentosa irmã,D. Amelia de Nesquita, \\
pianista tanibem de raça, pondo no \\
seu jigo uma destreza elegante, rara \\
em mãos femininas, as qualidades \\
que acıma mencionámos lêem largo e \\
brilhante realce. Sente-se que o poeta \\
soffre, chora e depois exulta de feli. \\
cidade, conforme explicı a estrophe \\
em francez do programm. Ha alli \\
phrases deliciosas que falam, gemem,
\end{tabular}

Figura 3: Sobre a matinée-concertante no Palacio Crystal

Fonte: Gazeta de Petropolis. Salões e Palcos. Maestro Carlos de Mesquita RJ, anno XI, n. 13, 29 de janeiro de 1901, p. 2.

Em 1901, a figura 3 expõe uma situação na qual Carlos de Mesquita divide o palco com a irmã, ambos como pianistas. A crítica refere-se a Amelia como "pianista também de raça" associando tal afirmação claramente a figura do irmão e, em seguida, ao afirmar "pondo no seu 
jogo uma destreza elegante, rara em mãos femininas", reitera a compreensão feita anteriormente ao expor conscientemente ou não que a profissionalização artística seria uma prerrogativa eminentemente masculina.

Outro exemplo desconcertante parte do biógrafo e esposo de Luiza Leonardo (1859-1926), Sílio Boccanera Júnior (1863-1938), que em seu texto biográfico sobre a artista, ao referir-se à responsabilidade, ao patrocínio de seus estudos no Conservatório de Música de Paris e à pensão que garantiu que a artista pudesse sobreviver até que encontrasse um posto de trabalho em sua pátria, providos por D. Pedro II, Sílio ressaltou: "a quem deve toda a educação artística e todo o cultivo literário que possúe, e que a torna, hôje, espirito superior e admiravel, excepcional para o séxo a que pertence" (BOCCANERA JÚNIOR, 1923, p. 360). Novamente percebemos no discurso masculino que, quando a musicista se destaca publicamente, a interpretação corrente pelo patriarcado é a de que ela se distanciou de seu sexo e se assemelhou aos homens.

Outro caso ocorreu com a Condessa Rafaela de Rozwadowska (1816-1906), em sua estreia pública no salão do Theatro Provisório, em 4 de fevereiro de 1853. Aos olhos da crítica impressa, essa estreia não foi muito festejada, conforme declarou certo folhetinista:

o concerto da Sra. condessa Rozwadowska, que não esteve muito concorrido apezar de ter sido honrado com a presença de Suas Magestades. A condessa tocou bem, é eximia pianista, mas não de força superior à de algumas dilletanti nossas, especialmente de uma que mora em Catumby (Folhetim do Jornal do Commercio de 6 de fevereiro de 1853 - A Semana).

Na percepção de outro folhetinista sobre o referido concerto ${ }^{3}$, conforme apontou Avelino Pereira (2019), pode-se dizer que ele reconheceu o talento da pianista, ao passo que tripudiou dela por ser desconhecida do público, estrangeira, mulher, e também por certa incapacidade do crítico em assimilar obras desconhecidas de música instrumental, por estar muito habituado e até formatado ao repertório de canto e ópera em voga no contexto carioca. Tal crítica não foi assinada, mas o palpite de Pereira parece-me certeiro ao inferir que seria José de Alencar, haja vista a sua ironia típica e o seu gosto musical bastante estrito, conforme observado por Tinhorão (1992, p. 127-128). Vale a pena observar na integra o discurso do folhetinista:

Sra. Condessa Ro... Ro... Rozwadowska (dominus tecum). Perdoem amigas leitoras, se não posso pronunciar os nomes de origem polaca, sem dar um espirro. Apreciei a sua excelente execução, e ajudei a aplaudi-la com esta mão que nunca me doa para poder vitoriar o mérito. A Sra. Condessa toca piano admiravelmente, por mais que eu aplicasse os ouvidos não the notei que faltasse à nota alguma das muitas que tocou, que não pude contar, mas que estou persuadido não foram menos de mil: o seu talento sobressaiu, principalmente no dueto que executou com o Sr. Noronha. (...) como não há quadro sem reverso, não se enfade a Sra. Condessa se lhe disser que não foi feliz na escolha de suas peças; os meus ouvidos mereciam coisa mais fina ${ }^{4}$.

No entanto, segundo a análise de Avelino Pereira (2019), o programa do concerto, divulgado no Correio Mercantil $1^{5}$ no dia do evento, aponta que as ditas "modinhas polacas $e$ húngaras" mencionadas pelo folhetinista citado anteriormente, eram na verdade peças de Chopin e Liszt, dois dos mais importantes pianistas e compositores europeus do período, cujas

\footnotetext{
${ }^{3}$ Folhetim do Diario - Para quem não assistiu. Diario do Rio de Janeiro, ano XXXII, n. 36, 06 de fevereiro de 1853 , p. 1.

${ }^{4}$ Folhetim do Diario - Para quem não assistiu. Diario do Rio de Janeiro, ano XXXII, n. 36, 06 de fevereiro de 1853 , p. 1.

${ }^{5}$ Espetáculo. Correio Mercantil, Rio de Janeiro, anno X, n. 35, 04 de fevereiro de 1853, p. 4.
} 
composições permaneceram no repertório pianístico do momento, mas que naquele tempo eram ainda desconhecidas do público brasileiro. Além deles, a condessa executou obras de Thalberg, Schulhoff e Willmers, três pianistas-compositores de notável virtuosismo no século XIX. Pela escolha de repertório anunciada, pode-se inferir que a pianista tinha apurado domínio técnico e grande destreza, sobre o qual o folhetinista desdenhou dizendo das "muitas notas que tocou", que "não foram menos de mil". Desse modo, diante das evidências expostas, não nos parece razoável compará-la a uma diletante.

Simioni (2008), igualmente, identifica o tema da mulher que se masculinizava ao se profissionalizar como uma tópica de época. Ele esteve presente na literatura médica, nas crônicas de jornais, nos romances, na pintura, nas mentalidades individuais e passava constantemente na crítica de Gonzaga Duque sobre as pintoras nos anos finais do século XIX e início do século XX. A mulher de gênio era então compreendida como exceção, excrescência, conforme vimos nos casos de Amelia de Mesquita e Luiza Leonardo apresentados anteriormente, ou até mesmo ameaça.

Analisando o caso da profissão artística de pintoras e de escultoras na passagem do século XIX para o século XX, Simioni destaca que as simbologias relacionadas a ação profissional dessas mulheres eram complexas e desfavoráveis a elas: "se as artistas interiorizassem as expectativas acerca da arte feminina jamais romperiam com os estigmas do amadorismo, por outro lado, quando profissionalizadas, corriam o risco de ser tachadas de masculinas, e, assim, de se verem excluídas do próprio gênero" (SIMIONI, 2008, p. 63).

Convém notar que a autora encontra sinais bastante claros que esse grupo profissional feminino estava sendo separado em um nicho de gêneros artísticos, como a pintura de flores, de paisagens, de miniaturas, de natureza morta, de quadros de cotidiano, de pinturas decorativas e, por fim, de copistas, um patamar desvalorizado na hierarquia artística do Oitocentos, mas que para as características imputadas a elas, que eram: sensíveis, detalhistas, conservadoras, imitativas e dóceis, naquele tempo, parecia o ideal (SIMIONI, 2008).

Não identifiquei claramente o que seria o equivalente à essa compreensão sobre arte feminina na música nesse período. Entretanto, por meio do conceito de patriarcado musical elaborado por Lucy Green (2001) tem-se uma pista relevante para constituir o significado de que o trabalho musical público das mulheres, quando baseado nas características de seu trabalho musical privado - no ensino de piano e de canto, nas composições destinadas ao público amador e nos concertos com as peças favoritas de suas alunas -, de certo modo, criava um nicho para a arte feminina na música. Porém, dentro dessa divisão do trabalho musical baseada em uma esfera pública de maioria masculina e uma esfera privada de maioria feminina, nessa combinação entre tolerância e repressão, acordo e oposição protagonizado pelas mulheres profissionais da música, houve espaço também para rupturas com esse paradigma, no qual localizamos mulheres autônomas e profissionais como Amelia de Mesquita, Luiza Leonardo, Cinira Polonio (18571938) e Viúva Guerreiro (1858-1936), que se destacaram na vida pública pelo mérito de seus trabalhos, o que certamente abalou as certezas de que fossem naturalmente inferiores.

Retomando a discussão sobre o amadorismo como uma condição feminina, outra explicação que aparece na linguagem associada à divulgação dos trabalhos dessas trabalhadoras fica evidente com a palavra discípula e a consequente relação com um mestre. A ideia de uma artista em formação reforça a condição de amadora, eterniza a relação hierárquica entre a aprendiz e o seu mestre. Vejamos alguns exemplos: 
- HUMA Sra. estrangeira, pianista, chegada ha pouco tempo a esta capital, e discipula do conservatorio de Paris, deseja tomar algumas discipulas, e tambem pretende ensinar por casas particulares; dirigir-se á rua da Alfandega n. 133.

Figura 4: Anúncio - Fonte: Annuncios. Jornal do Commercio, RJ, n. 224, 1838.

Na figura 4, vimos que os elementos que esboçam a identidade dessa pessoa são: estrangeira, pianista e discípula do conservatório de Paris, fora isso, não sabemos seu nome, sua nacionalidade, sua idade, seu estado civil, tudo isso, porque aparentemente seriam informações triviais, desnecessárias. O primordial seria o destaque ao fato de ser estrangeira, pianista e discípula do conservatório de Paris, isso era o suficiente para o fim almejado "tomar algumas discipulas" e "ensinar por casas particulares".

Figura 5: Lições de Piano

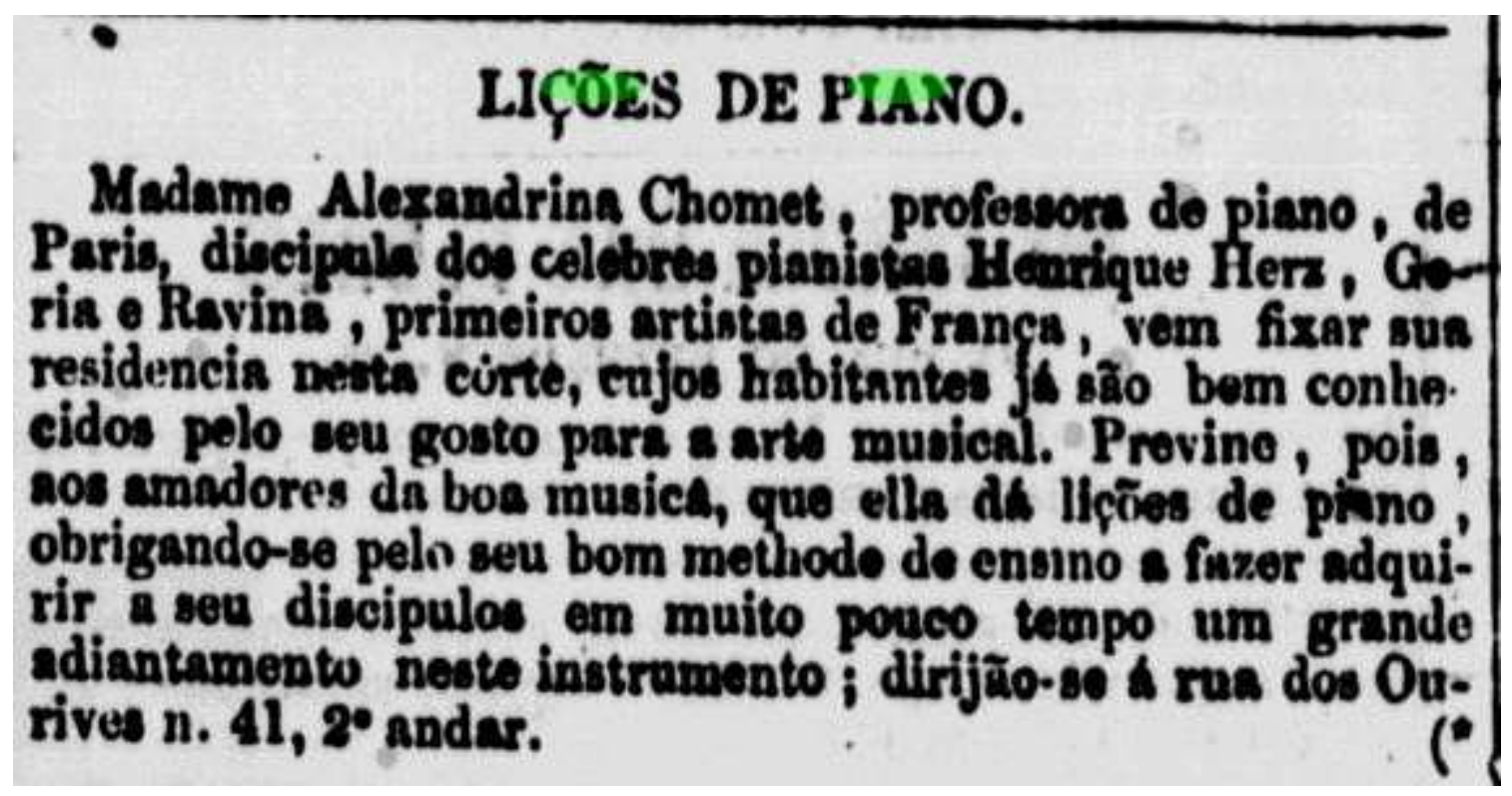

Fonte: Annuncios. Jornal do Commercio, RJ, n. 224, 1852.

Já na figura 5, a Madame Alexandrina Chomet, professora de piano, destaca-se por ser "discipula dos celebres pianistas Henrique Herz, Geria e Ravina, primeiros artistas de França". Nesse anúncio, temos mais elementos identitários sobre a anunciante, sabemos que ela era de Paris, por isso, ela usa o termo "Madame", era provavelmente casada ou viúva, e veio a fixar residência naquela corte, portanto, não estava de passagem. A ideia de solidificar um nome estava presente certamente, mas ressalta-se ainda assim o cartão de visitas inalterável: "discipula dos celebres pianistas Henrique Herz, Geria e Ravina, primeiros artistas de França". 


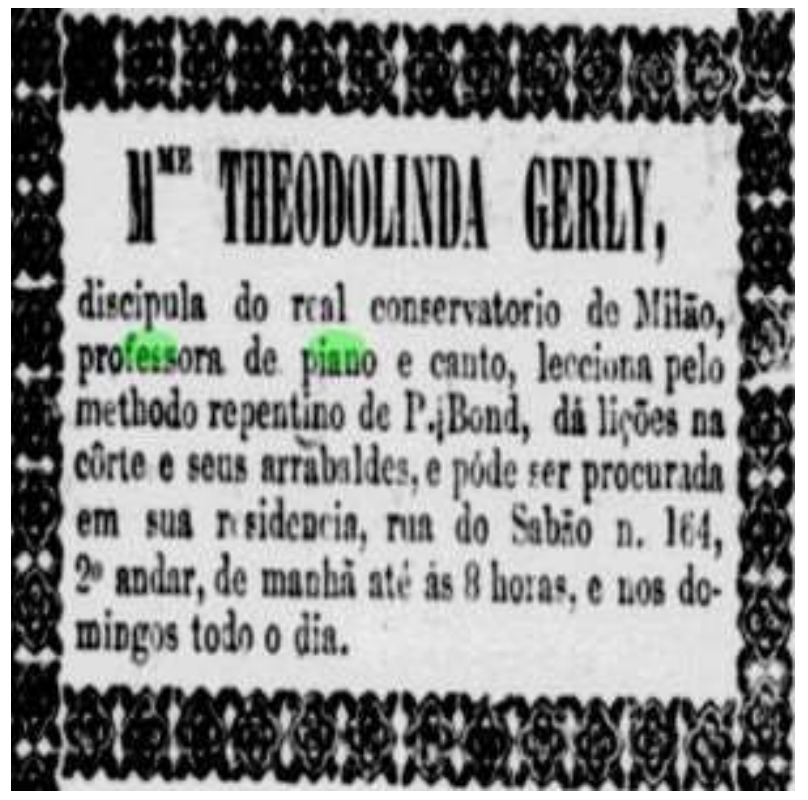

Figura 6: Mme. Theodolinda Gerly - Fonte: Annuncios. Jornal do Commercio, RJ, n. 106, 18 de abril de 1863.

Por fim, na figura 6, a Madame Theodolinda Gerly, embora fosse italiana, faz uso da forma de tratamento Madame porque era comum naquele período como uma forma de distinguir as estrangeiras das brasileiras. Era conhecida professora de piano e de canto, sobretudo, após ter concluído seu contrato com a companhia de Opera Lírica instalada no Theatro Lyrico. Tornou-se uma figura popular por ter organizado em sua residência um curso de música com método próprio aprendido com o Professor P. Bona do Conservatório de Milão. Ela dedicou-se ao ensino de discípulas particulares e também às meninas pobres que desejassem aprender a tocar piano e cantar gratuitamente. Encontramos vários anúncios fazendo menção ao fato, inclusive, informando que as aulas se davam simultaneamente para pagantes e não pagantes, o que já nos assinala a não ocorrência de distinção no tratamento dado às suas alunas. Além disso, promovia anualmente concertos com suas discípulas e artistas convidados. Aparentemente, ela estava no Brasil desde 1860 e encontramos registros sobre ela na imprensa até 1864, mesmo assim, em 1863, seu anúncio de trabalho reforçou: "discipula do real conservatorio de Milão".

O que há em comum nos três anúncios analisados é que, independentemente dos feitos dessas mulheres, lhes foi necessária uma chancela para que pudessem oferecer seus serviços: ser discípula de alguém ou de algum lugar. Evidentemente que os históricos de formação acompanham os sujeitos até o fim de suas vidas, de fato trata-se de um elemento de distinção no meio profissional, para homens e para mulheres, e isso não está em discussão. Nosso problema aqui consiste no uso de uma palavra que não reforça um estágio da vida, e sim, uma condição feminina, no caso, o constante uso do termo discípula no modo presente, que na verdade representa uma ação do passado. A impressão que isso gera é de que sem as instituições, sem seus mestres, constantemente impressos em seus anúncios, elas não poderiam atuar profissionalmente, e o fato era que elas já eram profissionais. Além disso, essa situação configurou um paradoxo que confinou as mulheres à condição de aprendizes ao reforçar que as discípulas ensinariam outras discípulas.

Outro elemento a ser explorado consiste na recorrente associação dessas profissionais da música aos seus familiares que, neste caso, eram célebres músicos. Já vimos essa relação com Amélia de Mesquita e o seu irmão Carlos de Mesquita, mas outras artistas passaram pelo mesmo constrangimento simplesmente porque era preciso para que elas pudessem existir naquela sociedade. Vejamos alguns exemplos: 


\section{4. - Concerto de piano, composto pelo celebre Bom- tempo, primeiro pianista e compositur de Portu- gal, executado pela joven Leopoldina Josepha dos Reis, filha e diseipula do beneficiado.}

Figura 7: Programa de Concerto - Fonte: Jornal do Commercio, RJ, n. 92, 1840.

$\mathrm{Na}$ figura 7, foi dada ênfase sobre a composição do célebre Bomtempo, primeiro pianista e compositor de Portugal, e a execução da peça apareceu em segundo plano, e em nível hierárquico abaixo do beneficiado, sob as palavras jovem, filha e discípula. Nota-se que o uso das palavras jovem e discípula se associam diretamente à palavra amadora, reforçando a ideia de elas serem iniciantes, imaturas. Já a relação parental traduz a ideia de que o conhecimento musical está no sangue, algo que aparece com frequência nos meios impressos. O nome da jovem aparece, felizmente, e assim pudemos verificar que, em 1867, ela reaparece como professora de piano e canto.

A filla do insigne prolessor Lino José Nunes, canto e piano, r. do Rezende, 20.

Figura 8: Professores de Piano - Fonte: Almanak Administrativo, Mercantil e Industrial do Rio de Janeiro. Professores de música instrumental e vocal, edição 00010, p. 382, 1853.

Na figura 8, chama a atenção o fato de que em um periódico que concentra nomes de profissionais atuantes no setor de serviços daquela sociedade, simplesmente não apresentou o nome da professora de canto e piano, o que vem no seu lugar é "A filha do insigne professor Lino José Nunes". Supõe-se que ele era uma figura conhecida e respeitada e nisso consiste o elemento de distinção dessa profissional totalmente apagada.

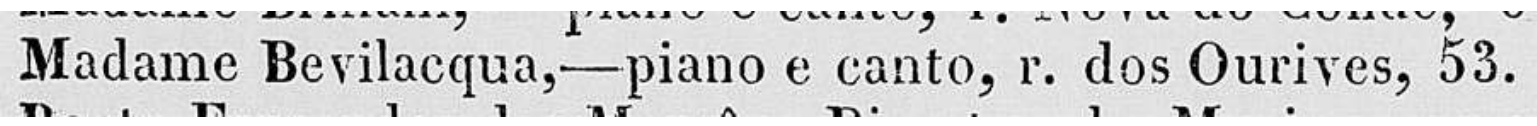

Figura 9: Professores de Piano - Fonte: Almanak Administrativo, Mercantil e Industrial do Rio de Janeiro. Professores de música instrumental e vocal, edição 00010, p. 382, 1853.

Por fim, na figura 9, apresenta-se Madame Bevilacqua, também sem nome próprio, mas com um sobrenome reconhecido. Estamos falando da esposa de Isidoro Bevilacqua (18131897), genovês, que chegou no Rio de Janeiro como professor de piano em 1835 e, em 1846, inaugurou o seu "armazém de pianos e música" e editora, que em pouco tempo tornou-se dos mais importantes no país. Em 1855, ele tornou-se mestre de música da família imperial. Ele e seu filho, Alfredo Bevilacqua, também foram professores de Luiza Leonardo, em 1866. O nome dos Bevilacqua, pai e filho, aparece regularmente nos livros de história da música brasileira, evidentemente porque consolidaram papéis importantes nessa história, entretanto, a Madame Bevilacqua não aparece, mesmo tendo sido também professora de piano e canto, ou seja, pertencente à mesma carreira profissional familiar.

Devemos salientar que nas trajetórias profissionais das musicistas, o cultivo da música no seio familiar foi um elemento agregador que potencializou, por sua vez, essa escolha profissional. Sendo assim, a assertiva de Pierre Bourdieu, embora em contexto diferente do nosso, reforça esse sentido sobre o que apontamos no tempo passado: "A música não são os discos e a eletrola dos vinte anos, graças aos quais descobrimos Bach e Vivaldi, mas o piano da família ouvido desde a infância e vagamente praticado até a adolescência [...]" (BOURDIEU, 1994, p. 97). 
Todavia, para a profissional da música que desejava e que tinha condições materiais para isso era preciso que ela se libertasse dessa dominação patriarcal, e algumas delas só puderam realizar essa conquista de si enquanto artistas com a oportunidade de completar seus estudos fora do país. A partir do nosso levantamento, as artistas que estudaram no exterior foram: Luiza Leonardo (França), Amelia de Mesquita (França), Cinira Polonio (Itália) e Gina de Araújo (1890-1960, França). Não tivemos acesso aos seus diários, às cartas, aos seus históricos acadêmicos, porém, é possível inferir e analisar o impacto que essa experiência causou sobre suas vidas, sobre as produções delas que temos em mãos.

A partir da experiência vivida, descrita e analisada por Simioni (2008) sobre as pintoras e escultoras brasileiras que foram estudar em Paris, é possível imaginar o que tal vivência significou na vida das profissionais da música que lá estiveram também, guardadas as devidas proporções, por ter sido uma vivência contemporânea a das musicistas brasileiras.

libertar-se significava romper os 'invisíveis laços' que a amarravam a um tipo de autoridade que era também artística, estilística. Como para Helena Pereira da Silva, é possível que a ida ao exterior, notadamente a Paris, fosse um caminho auspicioso para a conquista de si, base para o empreendimento da arte como profissão. Atravessar um oceano era um só tempo despedir-se dos constrangimentos familiares e ver surgir um mundo novo, com escolas artísticas ousadas, professores consagrados, exposições variadas, museus gigantescos... (SIMIONI, 2008, p. 147).

E também a partir da experiência narrada pela pintora de origem suíça, Louise Breslau, que foi aluna da Académie Julian e notabilizou-se como retratista, chegando a ser uma das mais reconhecidas artistas no gênero no começo do século XX. "Vocês não teriam jamais ideia do que a França representa para nós [...] um país capaz de tamanha delicadeza, de um entusiasmo tão puro, este país deve ser adorado! Ele nos provou que a mulher artista tem uma pátria sobre a terra" (SIMIONI, 2008, p. 149).

A grande maioria das profissionais da música não pôde sequer sonhar com essa possibilidade porque no corre da vida elas precisaram sobreviver e manter os seus vivos. Todavia, cultivar suas memórias é igualmente importante, porque junto com aquelas que gozaram de melhores condições de profissionalização e de mais anos de estudo, temos um grupo comum de profissionais, uma ação coletiva que vislumbrava um feminismo. Compreender a luta pela sobrevivência e sustento familiar por meio da música configurava um modo não convencional de reação das mulheres naquele período e, portanto, uma nova abordagem sobre o feminismo no século XIX no Brasil; afinal, são modos de resistir e refazer a imagem sobre o ser feminino no país (PAIXÃO; PAULA, 2021).

\section{Considerações finais}

Nota-se pela análise das fontes primárias que houve um esforço do patriarcado protagonizado por setores influentes da sociedade para criar a imagem de que as profissionais da música eram amadoras, e isso repercutiu sobre o futuro esquecimento delas. Os responsáveis por essa narrativa foram: os historiadores da música, os críticos musicais, os escritores e os jornalistas. Eles são os autores do cânone, ou seja, de um raciocínio argumentativo que relaciona determinados artistas, práticas, eventos, instituições e ideias que elaboram a compreensão sobre o passado, sobre o presente e também sobre as expectativas em relação ao futuro (SIMIONI, 2008).

Sobre os críticos e os jornalistas, obviamente poderiam ser homens ou mulheres, entretanto na maior parte das vezes não é possível saber quem são eles ou elas, pelo constante uso de pseudônimos 
e pelo uso de anonimato. Todavia, suas visões de mundo estavam sempre impressas ao falarem dos músicos e das musicistas. Também é sabido que no Oitocentos a grande maioria das críticas eram escritas por pessoas pouco entendidas sobre música. Algumas críticas eram mais especializadas como as de Oscar Guanabarino de Sousa Silva (1851-1937), de José Cândido de Andrade Muricy (18951984) e de Marisa Lira (1899-1971), mas não localizamos ainda críticas deles dirigidas às musicistas que pesquisamos, encontramos somente uma crítica feita por Andrade Muricy sobre Amelia de Mesquita na qual ele faz um criterioso levantamento sobre as composições dela.

Sobre o papel da crítica, Simioni (2008) faz um apontamento importante ao analisar a polêmica que ocorreu com a publicação do texto "A Propósito da Exposição Malfatti” de autoria de Monteiro Lobato no jornal O Estado de S. Paulo em 20 de dezembro de 1917. A repercussão dessa crítica afastou Monteiro Lobato dos modernistas de 1922 e até hoje é lida de maneira enviesada. Contudo, na leitura de Simioni:

Lobato era categórico em sua posição: criticara a artista porque, diferentemente dos colegas de profissão, levava-a sério independentemente de ser ela uma mulher. Sua recusa em perceber suas obras como fruto de um trabalho feminino que mereceria ser avaliado com critérios distintos de antemão destoava dos parâmetros correntes.

Lobato recusara peremptoriamente a ideia de que a própria arte tinha sexo. Ao fazê-lo, ainda que por meio de paradigmas esteticamente rígidos, refutava as crenças sobre capacidades distintas e desiguais que naturalmente perpassavam os sexos. Ao tomar a sério a produção de Anita, colocara na ordem do dia a possibilidade de uma artista, ser compreendida como uma profissional das artes e não mais tão-somente como uma amadora (2008, p. 81-82).

É possível questionar esses "paradigmas esteticamente rígidos" utilizados pelo autor da crítica ao se referir ao trabalho de Anita Malfatti, no entanto, ao que parece, o que mais incomodou a época foi o fato de ter colocado a artista num patamar de igualdade perante os homens, sob um olhar severo, mas sério, que ainda não localizamos nas críticas sobre as musicistas pesquisadas nesse período. E as leituras enviesadas sobre esse fato, no nosso tempo, parecem submersas na mesma barreira.

Quanto aos historiadores, por sua atenção estar voltada ao cânone, percebe-se que seus pontos de partida, suas próprias questões de pesquisa, já excluem as mulheres de antemão. E ao ler as obras da historiografia musical brasileira percebe-se o quanto a presença de homens e de mulheres é pouco equilibrada; quando se encontra um nome feminino não é raro que se discorra sobre ele em um espaço de meia a uma página, por exemplo. A visão benjaminiana sobre a história na qual o passado soterrado precisa ser constantemente escavado, revolvido, para que o fato, a camada mais preciosa, possa ser encontrada sob escavação rigorosa parece ser pouco praticada por certos historiadores. Essa visão de passado não acabado, mas em movimento, não como algo que não existe mais, mas como algo que persiste, que perdura, como dores do presente, é exercitada nesse trabalho de pesquisa para que essas musicistas sejam lembradas e pensadas num sentido transformador da realidade atual (BENJAMIN, 2020)

\section{Referências}

ALMANAK Administrativo, Mercantil e Industrial do Rio de Janeiro. Professores de música instrumental e vocal. edição 00010, Rio de Janeiro, p. 382, 1853. 
BENJAMIN, W. Sobre o conceito de história. Trad. A. Müller e M. Seligmann-Silva. São Paulo: Alameda, 2020.

BOCCANERA JUNIOR, S. Autôres e actôres dramáticos bahianos, em especial: biographias. Bahia: Imprensa Official do Estado, 1923.

BOURDIEU, P. Gostos de classe e estilos de vida. In: ORTIZ, R. (Org.). Pierre Bourdieu Sociologia. São Paulo: Ática, 1994, p. 82-121.

BUITONI, D. S. Mulher de papel: a representação da mulher na imprensa feminina brasileira. São Paulo: Edições Loyola, 1981.

GAZETA DE PETROPOLIS. Salões e Palcos: Maestro Carlos de Mesquita. Rio de Janeiro, anno XI, n. 13, 29 de janeiro de 1901, p. 2.

GREEN, L. Música, género y educación. Trad. Pablo Manzano. Madrid: Ediciones Morata, 2001.

JORNAL DO COMMERCIO. Rio de Janeiro, n. 224, 1838.

JORNAL DO COMMERCIO. Rio de Janeiro, n. 92, 1840.

JORNAL DO COMMERCIO. Rio de Janeiro, n. 224, 1852.

JORNAL DO COMMERCIO. Folhetim - a semana. Rio de Janeiro, anno XXVIII, n. 37, 06 de fevereiro de 1853 , p. 1.

JORNAL DO COMMERCIO. Rio de Janeiro, n. 106, 18 de abril de 1863.

JORNAL DO COMMERCIO. Rio de Janeiro, anno 63, n. 360, 28 de dezembro de 1885, p. 1.

JORNAL DO COMMERCIO. Rio de Janeiro, n. 82, 23 de março de 1897, p. 3.

LUCA, T. Magazines and the writing of history: some interpretative challenges. In: ABREU, M.; SILVA, A. (Org.). The cultural revolution of the nineteenth century: theatre, the book-trade and reading in the transatlantic world. New York/ London: I. B. Tauris, 2016, p. 44-68.

PAIXÃO, A. H.; PAULA, P. A. Os modos de vida das musicistas no Rio de Janeiro oitocentista. Em Pauta: Revista da Faculdade de Serviço Social da Universidade do Estado do Rio de Janeiro, Rio de Janeiro, n. 47, v. 19, p. 202-216, 2021.

PEREIRA, A. R. Mulheres compositoras no Rio de Janeiro oitocentista: a Condessa Rozwadowska. In: CARVALHO, M. P.; DURÃES, M.; ANDRADE, V. S. (Org.). Movimentos, trânsitos \& memórias: novas perspectivas (século XVII-XIX). Niterói: ASOEC-UNIVERSO, 2019, p. 286-301.

SIMIONI, A. P. C. Profissão artista: pintoras e escultoras acadêmicas brasileiras. São Paulo: Edusp, 2008. 
TINHORÃO, J. R. A música popular no romance brasileiro: século XVIII-século XIX. Belo Horizonte: Oficina de Livros, 1992.

WILLIAMS, R. Palavras-chave: um vocabulário de cultura e sociedade. São Paulo: Boitempo, 2007.

\section{Sobre a autora}

Patricia Amorim de Paula. Pedagoga e Mestra em Educação pela Faculdade de Educação da Unicamp. É doutoranda na Faculdade de Educação da Unicamp com bolsa da Fundação de Amparo à Pesquisa do Estado de São Paulo (Fapesp).

E-mail: paulaapatricia1@hotmail.com. 